\title{
Dissecting aneurysms of the distal segment of the posterior cerebral artery: clinical presentation and endovascular management
}

\author{
Zenghui Qian ${ }^{1,2+}$, Xin Feng ${ }^{1,2+}$, Huibin Kang ${ }^{1,2}$, Xiaolong Wen ${ }^{1,2}$, Wenjuan $\mathrm{Xu}^{1,2}$, Youxiang Li ${ }^{1,2}$, Chuhan Jiang ${ }^{1,2}$, \\ Zhongxue $\mathrm{Wu}^{1,2}$ and Aihua Liu ${ }^{1,2^{*}}$
}

\begin{abstract}
Backgroud: We aimed to evaluate the clinical presentations and report the acceptable clinical and angiographic outcome of the distal posterior cerebral artery (PCA) dissecting aneurysms with parent artery occlusion (PAO).

Methods: From June 2006 to July 2013, 26 patients with PCA dissecting aneurysms were planned to be treated via endovascular PAO in our institution. Fourteen patients had ruptured aneurysms, and twelve patients had unruptured aneurysms. The endovascular modalities were the following: 1) PAO $(n=19), 2)$ palliative embolization $(n=5)$, and 3$)$ proximal PAO $(n=2)$. Glasgow Outcome Scale (GOS) was used to assess the clinical outcome.

Results: The procedure was technically successful in all cases. In the PAO and proximal PAO group, all of the immediate angiography showed occlusion of the parent vessel, and follow-up imaging showed no recurrence of the aneurysms. In the palliative embolization group, one of five patients was died of rebleeding after the procedure, and follow-up digital subtraction angiography (DSA) showed the other four aneurysms recurred. Five procedure related complications occurred totally: rebleeding $(n=1)$, hemiparesis $(n=2)$, and hemianopsia $(n=2)$.

Conclusion: Dissecting aneurysms are dynamic lesions with variable and unpredictable evolution and a thorough treatment is warranted. Sacrificing the parent artery appears to be well tolerated for distal segment of PCA. We propose that this technique could be the first treatment option in treating dissecting aneurysms in this location. However, palliative occlusion of distal PCA dissecting aneurysms is not an advisable treatment option.
\end{abstract}

Keywords: Dissecting aneurysm, Embolization, Occlusion, Posterior cerebral artery

\section{Background}

Posterior cerebral artery (PCA) dissecting aneurysms account for less than $1.2 \%$ of all intracranial aneurysms, with most located at P2 or distal segment of the vessel [1]. The major clinical presentations in this lesion are subarachnoid hemorrhage (SAH) and brain ischemia. Due to anatomic location of the PCA (richness of perforating branches, proximity to upper brain stem and lower cranial nerves), their surgical treatment is associated with significant risk

\footnotetext{
* Correspondence: liuaihuadoctor@163.com

†Equal contributors

${ }^{1}$ Beijing Neurosurgical Institute, Capital Medical University, Beijing 100050, China ${ }^{2}$ Department of Interventional Neuroradiology, Beijing Tiantan hospital, Capital Medical University, No. 6, Tiantan Xili, Dongcheng District, Beijing

100050, China
}

(c) The Author(s). 2017 Open Access This article is distributed under the terms of the Creative Commons Attribution 4.0 International License (http://creativecommons.org/licenses/by/4.0/), which permits unrestricted use, distribution, and reproduction in any medium, provided you give appropriate credit to the original author(s) and the source, provide a link to the Creative Commons license, and indicate if changes were made. The Creative Commons Public Domain Dedication waiver (http://creativecommons.org/publicdomain/zero/1.0/) applies to the data made available in this article, unless otherwise stated. of neurologic complications [2, 3]. Endovascular technique enables treating these lesions without craniotomy and the risks related to surgical manipulation. However, in some situations, endovascular reconstructive approach is impossible for their dissecting nature, therefore, a deconstructive approach becomes inevitable. In the present study, a consecutive series of 26 patients harboring distal PCA dissecting aneurysms allocated for parent artery occlusion (PAO) in a single center was retrospectively analyzed.

\section{Methods}

Ethics statement

The study protocol was approved by the institutional review board at our hospital. All patients gave written 
informed consent to participate and the privacy of patients was strictly protected.

\section{Patients and aneurysm characteristics}

From June 2006 to July 2013, 109 PCA aneurysms were treated by endovascular approach in our institution. During this period, 26 patients with distal PCA dissecting aneurysms comprising approximately $23.8 \%$ of the total number were planned to be treated by immediate PAO or staged parent vessel and aneurysm occlusion. There were 14 men (53.8\%) and 12 women (46.2\%); ranging in age from 5 to 73 years (mean age $40.1 \pm 13.7$ years), and 18 patients were in $30-50$ years $(18 / 26,69.2 \%)$. The clinical presentation included SAH $(n=14, n=53.8 \%)$, headache $(n=6, n=23.1 \%)$, hemianesthesia or hemiparesis $(n=4$, $15.4 \%)$, visual symptom $(n=2,7.7 \%)$. Computed tomography $(\mathrm{CT})$, magnetic resonance imaging (MRI) or digital subtraction angiography (DSA) were performed before interventional procedure to assess the nature of the aneurysm. The diagnosis of a PCA dissecting aneurysm was essentially based on the characteristic features demonstrated on DSA and aided by MRI. Aneurysms were defined as dissecting aneurysms if the following characteristics were detected: 1) The radiological features of DSA which including narrowed irregular or segmental stenosis, occlusion, irregular fusiform or aneurysmal dilation, pearl-and-string sign, double lumen, and retention of contrast agent; 2) MRI confirmed a disordered wall pathological features (double lumen, intimal flap, and intramural hematoma) [4]. A 3-D DSA was performed to assess the size of the aneurysm. According to the longitudinal diameter, the aneurysms size were defined as large $(\geq 10 \mathrm{~mm})$, small $(<10 \mathrm{~mm})$.

\section{Treatment}

3-D DSA (Neurostar, Siemens Medical Solutions, Erlangen, Germany) was performed in all 26 patients before interventional procedures. The endovascular treatments were performed in the neuroangiography suite, and the patients received general anesthesia and systemic heparinization. In these patients, 2000-3000U of heparin (Gansuna; Qianhong, Jiangsu, China) was administered at the beginning of the procedure, followed by $1000 \mathrm{U}$ every hour until completion. Heparin (3000 IU/L) was also administered in the flushing solutions. A $6 \mathrm{~F}$ guiding catheter was advanced in the vertebral artery, and selective catheterization of the PCA was performed. For patients with fetal PCA or aplastic P1, we performed an internal carotid artery approach instead. A microcatheter (ev3 Micro Therapeutics Inc.; Irvine, California, USA) was introduced by a microguidwire (ev3 Micro Therapeutics Inc.; Irvine, California, USA) in a coaxial fashion through the $6 \mathrm{~F}$ Envoy guiding catheter (Cordis Corporation; Miami Lakes, Florida, USA), followed by selective catheterization of the artery with the aneurysm in each case. The tip of the microcatheter was placed into the aneurysm or proximal PCA, and parent artery should be occluded very proximal to the aneurysm. The vast majority of the deployed coils were bare platinum, including the Guglielmi Detachable Coil (Boston Scientific; Freemont, California, USA), MicroPlex Coils (MicroVention Inc.; Tustin, California, USA), or Trufill Orbit Coils (Cordis Corporation; Miami Lakes, Florida, USA). A small number of coated bioactive Cerecyte coils (MicroVention Inc.; Miami Lakes, Florida, USA) were also used. The standard method is occluding the aneurysm by coils and extending into the proximal PAO. For two large aneurysms, we use proximal occlusion for fearing of mass effect after trapping procedure or perforation of the fragile aneurysmal wall. The management for palliative embolization of dissecting PCA is to place the microcatheter at the dissected site in the true lumen and then occlude the lumen during the initial treatment. Early in our experience, five patients were performed palliative embolization (Raymond scale 2 and Raymond scale 3) for the first procedure in order to avoid infarction of the PCA territory. Angiography was performed after every coil placement to confirm occlusion of the parent artery and the aneurysm. Heparinization was continued for 24 hours in all patients after procedure, and then changed into low molecular heparin for hypodermical injection and continued for 2 or 3 days.

\section{Clinical and angiographic analysis}

The clinical and angiographic data were reviewed respectively. Clinical and follow-up outcomes were assessed at hospital discharge by using the Glasgow Outcome Scale (GOS). Follow-up data were collected by using the most recent outpatient records. All aneurysms were evaluated angiographically immediately after treatment. The angiogram outcomes were classified as follows: 1) complete, or 2) incomplete according to immediate angiogram after procedure. For the patients who underwent palliative embolization, follow-up angiography were performed routinely in 1-3 months.

\section{Results}

The location, size of these aneurysms, and the clinical presentation, modality of embolization, periprocedural complications, clinical outcome, angiogram outcome and follow-up outcome (including GOS and symptoms) were summarized in Table 1 . The five patients who were intended to be palliative embolization were summarized in Table 2.

\section{The nature and location of aneurysms}

According to the imaging presentation, all 26 aneurysms were diagnosis as dissecting aneurysms, and could not be easily treated with reconstructing 
Table 1 The characteristics of 26 aneurysms

\begin{tabular}{|c|c|c|c|c|c|c|c|c|c|c|}
\hline No. & $\begin{array}{l}\text { Age/ } \\
\text { Sex }\end{array}$ & Location & size & Symptoms & First Trx & $\begin{array}{l}\text { Immediate } \\
\text { angiogram }\end{array}$ & complications & $\mathrm{F} / \mathrm{u}(\mathrm{m})$ & $\operatorname{Re}-\operatorname{Tr} x(m)$ & Clinical/angio F/u \\
\hline 1 & $16 / F$ & $\mathrm{P} 2(\mathrm{R})$ & small & Headache & $\mathrm{PAO}$ & Complete & None & 25 & No & $\begin{array}{l}\mathrm{GOS}=5, \text { no symptom/ } \\
\text { no recurrence }\end{array}$ \\
\hline 2 & $42 / \mathrm{M}$ & P2 (L) & small & $\mathrm{SAH}$, hemianesthesia (R) & $\mathrm{PAO}$ & Complete & None & 17 & No & $\mathrm{GOS}=5$, no symptom \\
\hline 3 & $24 / F$ & P2 (L) & large & Headache & Coiling & Partial & None & 10 & Yes(6) & $\begin{array}{l}\mathrm{GOS}=5, \text { no symptom/ } \\
\text { no recurrence }\end{array}$ \\
\hline 4 & 39/M & P4 (L) & large & Headache & $\mathrm{PAO}$ & Complete & None & 25 & No & $\mathrm{GOS}=5$, no symptom \\
\hline 5 & $46 / F$ & $\mathrm{P} 2(\mathrm{R})$ & small & $\mathrm{SAH}$, hemiparesis $(\mathrm{L})$ & $\mathrm{PAO}$ & Complete & None & 8 & No & $\begin{array}{l}\mathrm{GOS}=5, \text { no symptom/ } \\
\text { no recurrence }\end{array}$ \\
\hline 6 & $36 / \mathrm{M}$ & P3 (L) & large & Headache & $\mathrm{PAO}$ & Complete & None & 6 & No & $\begin{array}{l}\mathrm{GOS}=5, \text { no symptom/ } \\
\text { no recurrence }\end{array}$ \\
\hline 7 & $48 / \mathrm{M}$ & $\mathrm{P} 2(\mathrm{R})$ & small & $\mathrm{SAH}$ & $\mathrm{PAO}$ & Complete & None & 5 & No & $\mathrm{GOS}=5$, no symptom \\
\hline 8 & $27 / F$ & $\mathrm{P} 2(\mathrm{R})$ & large & $\mathrm{SAH}$ & $\mathrm{PAO}$ & Complete & None & 7 & No & GOS $=5$, no symptom \\
\hline 9 & $40 / F$ & P3 (L) & large & Headache & $\mathrm{PAO}$ & Complete & None & 12 & No & $\begin{array}{l}\mathrm{GOS}=5, \text { no symptom/ } \\
\text { no recurrence }\end{array}$ \\
\hline 10 & $37 / F$ & P2 (L) & small & SAH,hemiparesis (R) & $\mathrm{PAO}$ & Complete & None & 6 & No & $\begin{array}{l}\mathrm{GOS}=5, \text { no symptom/ } \\
\text { no recurrence }\end{array}$ \\
\hline 11 & $44 / F$ & $\mathrm{P} 2(\mathrm{R})$ & large & SAH, hemiparesis (L) & Coiling & Partial & $\begin{array}{l}\text { Hemiparesis } \\
\text { aggravation }\end{array}$ & 3 & Yes (3) & $\begin{array}{l}\mathrm{GOS}=4 \text {, hemiparesis/ } \\
\text { no recurrence }\end{array}$ \\
\hline 12 & $30 / \mathrm{M}$ & P2-P3(L) & large & $\mathrm{SAH}$ & Coiling & Partial & None & 84 & Yes (4) & $\begin{array}{l}\mathrm{GOS}=5, \text { no symptom/ } \\
\text { no recurrence }\end{array}$ \\
\hline 13 & $40 / \mathrm{F}$ & P2 (L) & large & $\mathrm{SAH}$ & Coiling & Partial & Bleeding & 0 & No & $\mathrm{GOS}=1$, death \\
\hline 14 & $73 / F$ & $\mathrm{P} 2(\mathrm{R})$ & small & $\mathrm{SAH}$ & $\mathrm{PAO}$ & Complete & hemianesthesia & 10 & No & $\begin{array}{l}\mathrm{GOS}=4 \text {, hemianesthesia/ } \\
\text { no recurrence }\end{array}$ \\
\hline 15 & $56 / \mathrm{M}$ & $\begin{array}{l}\text { P1-2 } \\
\text { junction(L) }\end{array}$ & small & $\mathrm{SAH}$ & $\mathrm{PAO}$ & Complete & None & 3 & No & $\mathrm{GOS}=5$, no symptom \\
\hline 16 & $51 / F$ & $P 2(R)$ & large & $\begin{array}{l}\text { Hemiparesis, } \\
\text { hemianesthesia }(\mathrm{L})\end{array}$ & PAO & Complete & None & 6 & No & $\begin{array}{l}\mathrm{GOS}=4 \text {, mild hemiparesis } \\
\text { but return to work }\end{array}$ \\
\hline 17 & $47 / M$ & P2 (L) & large & diplopia & Proximal PAO & Complete & None & 6 & No & $\begin{array}{l}\mathrm{GOS}=5, \text { no symptom/ } \\
\text { no recurrence }\end{array}$ \\
\hline 18 & $5 / F$ & P2 (L) & large & $\mathrm{SAH}$ & Proximal PAO & complete & None & 12 & No & $\begin{array}{l}\mathrm{GOS}=5, \text { no symptom/ } \\
\text { no recurrence }\end{array}$ \\
\hline 19 & $49 / \mathrm{M}$ & $\begin{array}{l}\text { P2-3 } \\
\text { junction (R) }\end{array}$ & large & Hemiparesis (L) & $\mathrm{PAO}$ & Complete & None & 5 & No & $\mathrm{GOS}=4$, mild Hemiparesis \\
\hline 20 & $66 / M$ & $\mathrm{P} 3(\mathrm{R})$ & large & $\mathrm{SAH}$ & Coiling & Partial & None & 6 & Yes (3) & $\begin{array}{l}\mathrm{GOS}=5, \text { no symptom/ } \\
\text { no recurrence }\end{array}$ \\
\hline 21 & $30 / \mathrm{M}$ & P2 (L) & small & Headache & $\mathrm{PAO}$ & Complete & None & 12 & No & $\mathrm{GOS}=5$, no symptom \\
\hline 22 & $44 / \mathrm{M}$ & $\begin{array}{l}\text { P2-3 } \\
\text { junction(R) }\end{array}$ & small & Blurred vision & $\mathrm{PAO}$ & Complete & Hemianopsia & 4 & No & $\begin{array}{l}\text { GOS }=5 \text {, hemianopsia } \\
\text { partially recovered }\end{array}$ \\
\hline 23 & $37 / \mathrm{M}$ & P2 (L) & small & Hemiparesis (R) & $\mathrm{PAO}$ & Complete & Hemianopsia & 13 & No & $\begin{array}{l}\text { GOS }=4 \text {, Hemiparesis, } \\
\text { hemianopsia }\end{array}$ \\
\hline 24 & $41 / F$ & $\mathrm{P} 2(\mathrm{R})$ & small & $\mathrm{SAH}$, hemiparesis $(\mathrm{L})$ & $\mathrm{PAO}$ & Complete & None & 9 & No & $\mathrm{GOS}=5$, no symptom \\
\hline 25 & $35 / \mathrm{M}$ & P2 (L) & large & $\mathrm{SAH}$ & $\mathrm{PAO}$ & Complete & None & 7 & No & GOS $=4$, mild Hemiparesis \\
\hline 26 & $39 / M$ & $\mathrm{P} 3(\mathrm{R})$ & large & Hemiparesis (L) & $\mathrm{PAO}$ & Complete & None & 9 & No & $\begin{array}{l}\mathrm{GOS}=4 \text {, mild Hemiparesis/ } \\
\text { no recurrence }\end{array}$ \\
\hline
\end{tabular}

Abbreviations: PAO parent artery occlusion; GOS Glasgow outcome scale; SAH subarachnoid hemorrhage; F/u follow-up; Trx treatment

technique. The locations of aneurysms were classified according to Zeal et al. [5]: We defined P2-P4 as distal PCA as the P2, P3, and P4 segments are the true PCA system which are different from P1 segments in embryology [6].17 (65.4\%) in P2 segment, 4 (15.4\%) in P3, 3 (11.5\%) in P2-3 junction, 1 (3.8\%) in P1-2 junction, 1 (3.8\%) involved both P2 and P3 segment, and $1(4.3 \%)$ in P4. Among the 26 aneurysms, 11 (42.3\%) were small aneurysms and 15 (57.7\%) were large aneurysms. 
Table 2 The characteristics of 5 patients who received palliative embolization

\begin{tabular}{|c|c|c|c|c|c|c|c|c|c|c|}
\hline No. & Age/Sex & Location & size & Symptom & $\begin{array}{l}\text { Periprocedural } \\
\text { Complication }\end{array}$ & $\begin{array}{l}\text { Angio } \\
\text { F/u (m) }\end{array}$ & Recurrence & Re-Trx & $\begin{array}{l}\text { Re-Trx } \\
\text { modality }\end{array}$ & $\begin{array}{l}\text { Clinical F/u } \\
\text { (m)/outcome }\end{array}$ \\
\hline 3 & $51 / F$ & P2-3 junction/L & Large & Headache & None & 3 & Yes & Yes & PAO & $10 / \mathrm{GOS}=5$ \\
\hline 11 & $44 / F$ & $\mathrm{P} 2 / \mathrm{R}$ & Large & SAH, Hemiparesis (L) & Hemiparesis aggravation & 1 & Yes & Yes & PAO & $3 / \mathrm{GOS}=4$ \\
\hline 12 & $30 / M$ & P2-P3/L & Large & $\mathrm{SAH}$ & None & 2 & Yes & Yes & PAO & $84 / \mathrm{GOS}=5$ \\
\hline 13 & $40 / F$ & $\mathrm{P} 2 / \mathrm{L}$ & Large & $\mathrm{SAH}$ & Bleeding & 0 & - & - & - & $0 / \mathrm{GOS}=1$ \\
\hline 20 & $66 / M$ & $\mathrm{P} 3 / \mathrm{R}$ & Large & $\mathrm{SAH}$ & None & 2 & Yes & Yes & PAO & $6 / \mathrm{GOS}=5$ \\
\hline
\end{tabular}

Abbreviations: PAO parent artery occlusion; GOS Glasgow outcome scale; SAH subarachnoid hemorrhage; F/u follow-up; Trx treatment

\section{Palliative embolization of aneurysms}

Of 26 aneurysms, five were palliatively occluded with coils and initial occlusion was partial. One patient who initially presented with SAH of a large ruptured P2 aneurysm, died 3 days later of rupture after embolization, one patient survived with aggravating hemiparesis and other three patients were clinically unremarkable at follow-up. Follow-up angiography at 1-3 months showed partial reopening and larger in 4 remaining cases, and all aneurysms were additionally treated with $\mathrm{PAO}$ which received stable complete occlusion at extended angiographic follow-up Fig. 1.

\section{PAO and proximal PAO}

19 of 21 patients were treated by aneurysmal lumen and parent artery occlusion, and the other Two underwent proximal PAO. The procedure was technically successful in all and resulted in 100\% occlusion of all the aneurysms Fig. 2. Three perioperative complications occurred in this series: one patient developed hemianesthesia after occlusion of the parent artery, other two patients had hemianopsia after procedure due to occipital lobe infarction, which were revealed by postoperative MR. The postoperative course of other patients was uneventful.

\section{Clinical and angiographic results}

These patients were discharged, on average, by postoperative day 4 (range, day 3 through day 6). All patients had a good outcome (GOS 5 or 4), except one who had GOS 1. Clinical follow-up ranged from 3 to 84 months (average, 12.4 months), no patient had neurologic deficits occurred in clinical follow-up. Of the 25 patients, 13 had follow-up angiography. In each of the thirteen patients, the angiogram showed no residual filling of the aneurysm.

\section{Discussion}

\section{pecific morphologic and clinical features of PCA aneurysms}

Aneurysms of the posterior cerebral artery are rare vascular lesions and represent about $0.7-2.9 \%$ of all intracranial aneurysms which usually present as nonsaccular or dissecting nature [7, 8]. Distal PCA aneurysms are less frequent than proximal ones, but they are more often fusiform and are more prone to rupture than proximal ones [9]. Dissecting aneurysms were diagnosed angiographically if the angiographic signs are the "pearl and string" sign, meaning an aneurysmal dilation preceding or following a stenosis, the "string" sign, signifying an arterial stenosis or occlusion, and the fusiform or saccular aneurysmal dilation with stagnation of contrast agent inside. Other less common signs include the wall pathological features (double lumen, intimal flap, and intramural hematoma). The natural history of distal segment dissecting PCA aneurysms is likely different from the more common saccular aneurysms, which present with specific clinical findings. They occur more frequently in young individuals with an average age of 38 years, as opposed to the 50-60 years for aneurysms at other sites of the intracranial circulation [10]. The majority of patients were in 30-50 years in this series, and the mean age was 40.1 years, a little older than previously reported. As some paper reported $[9,11]$, the most common presentation in our case series was $\mathrm{SAH}$ $(53.8 \%)$ secondary to aneurysmal rupture presenting with headache and focal neurological deficits corresponding to the vascular territory of the PCA. A complaint of headache prompted diagnostic inquiry in 6 of our 26 patients, which is the important sign to vulnerable dissecting, especially in young population. Ciceri et al. [12] report a $25 \%$ incidence of visual disturbances in patients harboring PCA aneurysms, with a P1 segment giant serpentine aneurysm compressing the optic chiasm had a bitemporal hemianopsia. In our series, two (7.7\%) patients had visual disturbances which were postulated as ischemic events resulting from arterial dissection or compression of adjacent optic tract. Other clinical symptoms, like hemiparesis and hemianesthesia in our study are also observed, due to their mass effects and surrounding brain parenchymal edema. Aneurysms in the PCA have a tendency to become large. The incidence of large aneurysms in our study is $57.7 \%$, higher than previously reported. Larger aneurysms may compress surrounding structures, leading to mass effects mentioned above [13]. 

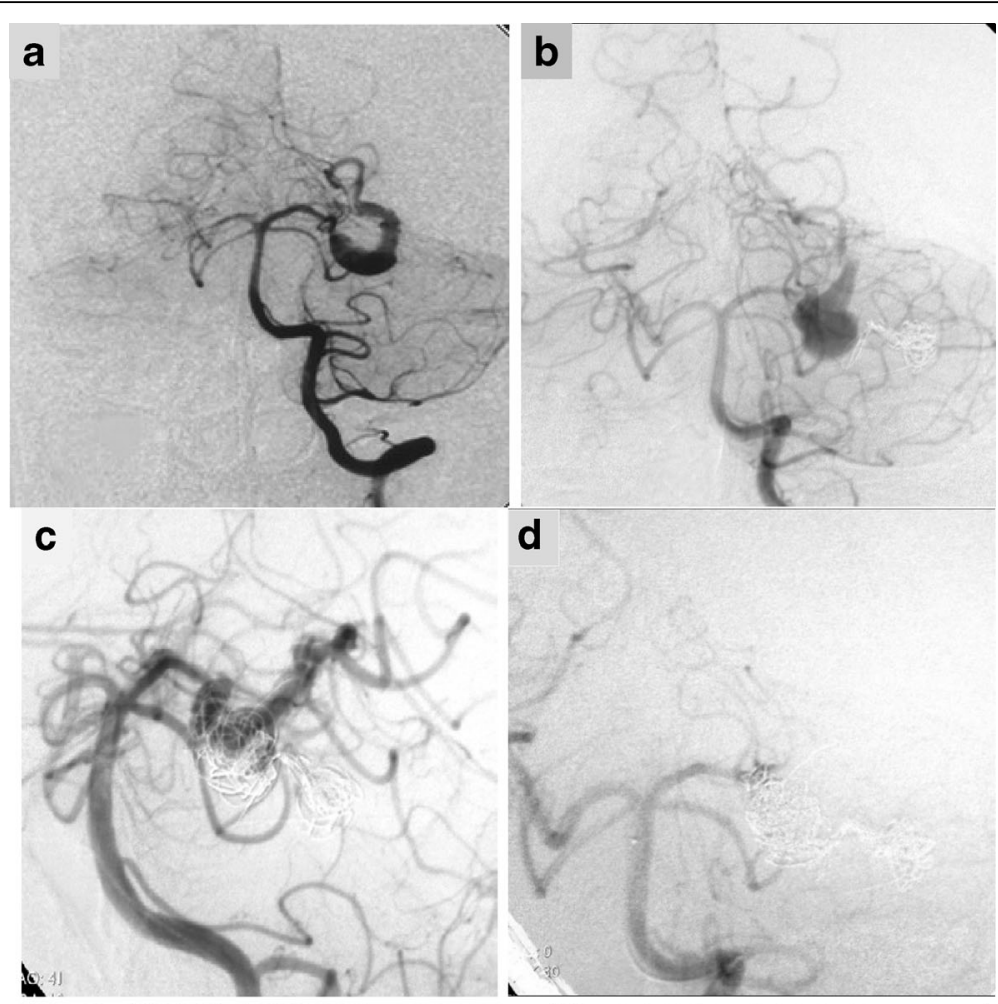

d

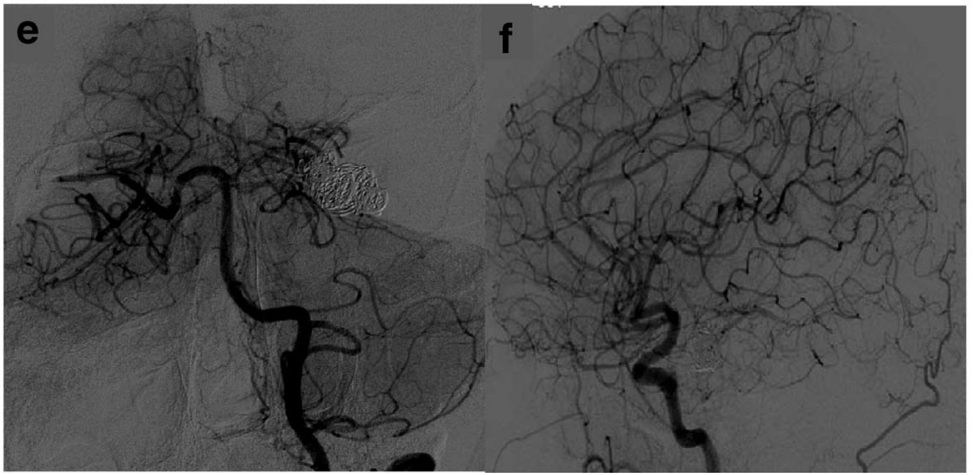

Fig. 1 a-f A large dissecting aneurysm of the P2-P3 segment of the PCA in a 30-year-old man presenting with SAH for 2 days. Anteroposterior projection of the left vertebralangiographyshowed partially embolization of the aneurysm after the first treatment (a) 2 months later, the follow-up angiography showed migration of the coils (b). Angiography images (c, d) showed Complete occlusion after PAO using detachable coils. Eighty-four months after PAO, Angiography images $(\mathbf{e}, \mathbf{f})$ showed the occluded aneurysm was stable, andleptomeningeal collateralcirculation was observed

\section{Treatment strategy}

Outcomes following neurosurgical treatment of intracranial aneurysms of the posterior circulation are worse than those of the anterior circulation especially in ruptured one. In a reported surgical series, the morbidity was $28.5 \%$ after treatment for the distal segment of PCA aneurysm [14]. These aneurysms constitute a relatively uncommon subgroup of intracranial aneurysms. In a series, presented by Wakhloo et al. [6] the dissecting aneurysms of PCA have a devastating natural history with up to $80 \%$ mortality in 5 years if untreated. Once ruptured to cause $\mathrm{SAH}$, dissecting aneurysms are associated with a high incidence of re-bleeding and a high mortality rate at the time of re-bleeding, indicating the need for early treatment [15]. Due to deeply located surrounding the midbrain, along the internal edge of tentorium, nearing many pivotal structures and their particular morphology, neurosurgical treatment of PCA is challenging and is associated with relatively high morbidity and mortality rates. Since the introduction of the GDCs and the publication of the International Subarachnoid Aneurysm Trial, endovascular treatment has become the method of choice in the treatment of intracranial aneurysms, particularly those in the posterior fossa [16]. 

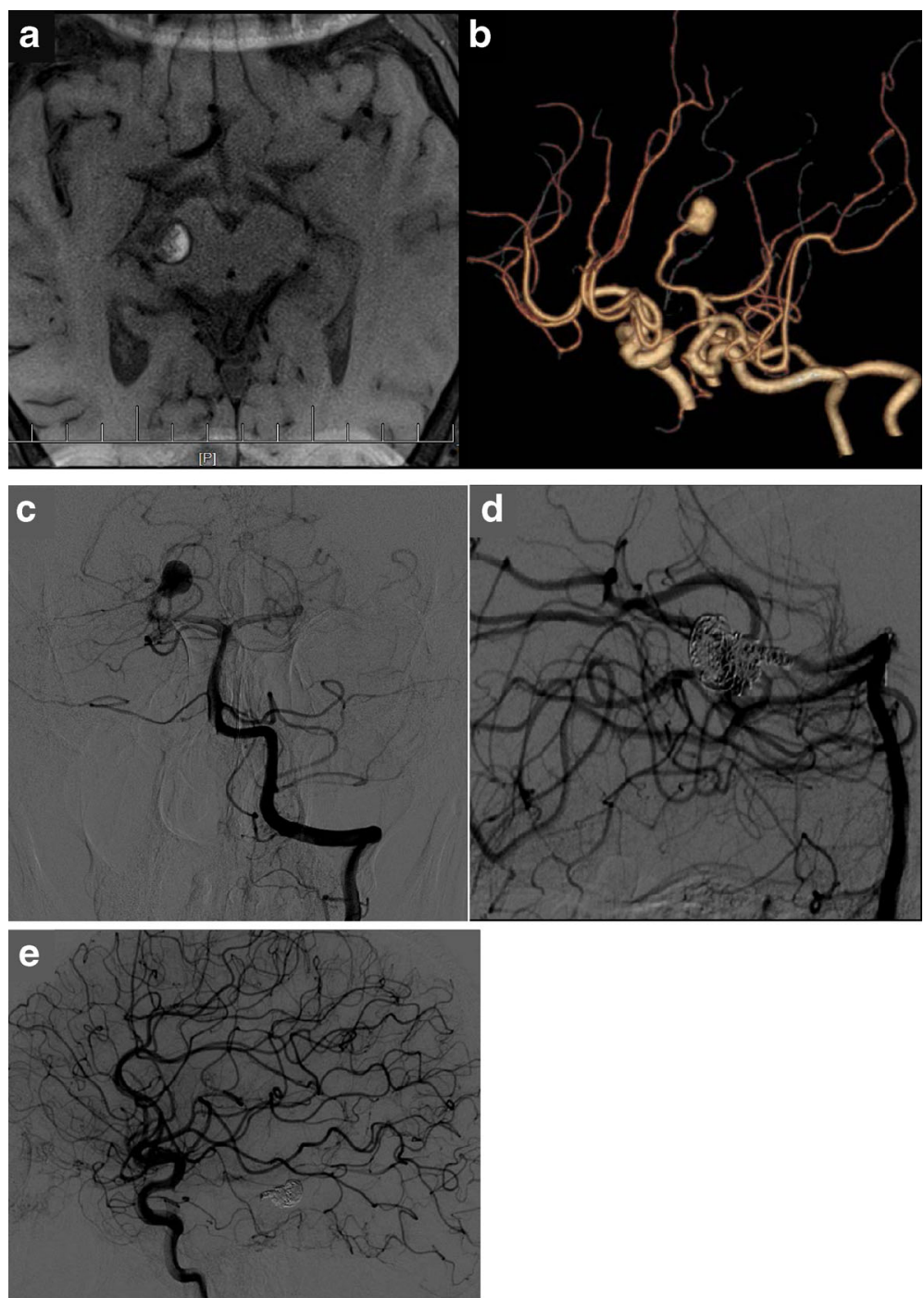

Fig. 2 A 49-year-old man presenting with Hemiparesis. Axial MR T1-weightedimage (a) shows a partially thrombosed large aneurysm compressing the right brainstem. CTA and anteroposteriorprojection of the left vertebralangiography images $(\mathbf{b}, \mathbf{c})$ show a large dissecting aneurysm in the P2P3 segment of the right PCA.Immediately after PAO (d), there isno residual aneurysm. Five-months control angiography (e) shows the retrograde filling of the cortical branches of the PCA

\section{Palliative embolization of aneurysms}

Ideally, the primary goal of endovascular treatment of PCA aneurysms is isolation of the aneurysms and preservation of the parent artery. In our 26 patients, five dissecting aneurysms were palliatively occluded with coils and initial occlusion was partial in all aneurysms. This treatment strategy is based on the theory that placed coils may lead a low aneurysmal blood inflow or blood stagnation that facilitate aneurysmal thrombosis which may provide a degree of protection from early rebleeding [17]. However, one patient suffered rebleeding 3 days later due to rupture of the coiled aneurysm, and follow-up angiography showed partial reopening and continuous growth in the remaining four aneurysms. In the literature, According to Ferns et al. [18], 28 partially thrombosed and primarily mid-to-large-size aneurysms treated by selective coil embolisation showed a $75 \%$ rate of reopening. In a series reported by Chang et al., 5 of 23 patients (22\%) with PCA dissecting aneurysms who underwent selective coil embolisation showed recurrence, and two of them died of rerupture [19]. Thus, a partially coiled dissecting aneurysms showed continuous growth, leading to a very poor prognosis. The possible reason is that it is sometimes difficult to occlude the entire dissected lesion and short-segment occlusion might gradually lead to coil compaction. Additionally, the microcatheter might be placed into the false lumen and occlude the lumen during the initial treatment. Thus, compressed true lumen may have reexpanded and recanalized with gradual healing several months later [13]. 
It is likely that continuous hemodynamic forces or migration of the coil mass into the intra luminal thrombus caused the extremely higher rates of reopening and bleeding. Furthermore, more than half of the dissecting aneurysms treated in our center were large aneurysms, and the angiographic and clinical prognosis of giant and large aneurysms is known to be worse than that of their smaller counterparts.

\section{PAO and proximal PAO}

The risk of recurrence and bleeding of the palliative embolic dissecting aneurysms is not eliminated, unless the point of dissection is eliminated. The ideal treatment modality is proximal artery ligation or trapping of the aneurysms with distal PCA bypass, due to limited experience with this technique, the overall risk of complications, including hemorrhage and infarction, is increased [13]. At present, endovascular occlusion of the dissected site has been accepted as a safe, minimally invasive, and reliable treatment for dissecting aneurysms when a test occlusion is tolerated or adequate collateral circulation is present. The basic management for endovascular occlusion of a dissecting aneurysm is to place the permanent occlusion device at the dissected site in the true lumen and then collapse the false lumen to induce thrombosis [14]. It is very important to keep in mind the anatomy of the PCA and its perforators during treatment because any decrease or obstruction of blood flow in the main PCA branches and/or perforators can cause cerebral infarction with significant morbidity [11]. Nevertheless, the exact location of the intimal flap where the dissection begins is difficult to identify. In view of this reason, the strategy of our treatment is to eliminate flow not only within the aneurysm but also within the dissected PCA segment, thereby decreasing the hemorrhagic risk. Kashiwazaki et al. [20] reported successful endovascular treatment of complex PCA aneurysms with parent vessel occlusion in 9 patients. Seven (78\%) of them who underwent PAO had cerebral infarction after the treatment. Fortunately, the area of cerebral infarction after PAO tended to be small and most of them didn't cause any symptom. Huang et al. [21] reviewed 98 cases of PCA aneurysms treated with PAO, no periprocedural bleeding happened, 16 (16.3\%) symptomatic ischemic complications were happened. A total of 12 (12.2\%) resulted in permanent neurologic deficit, but no procedure related death happened, and no hemorrhagic or ischemic event occurred in clinical follow-up. Although potentially carrying a risk for morbidity, according to the literature and our own experience (3/24 or $12.5 \%)$ including 2 visual field defect and one hemianesthesia, the risk for cerebral ischemia seems to be relatively low. The low incidence of symptomatic ischemic complication is related to the rich anastomotic collaterals that exist between the territory of the
PCA and that of other arteries which is the theoretical basis for PAO [22]. Furthermore, aneurysmal dilations of the dissected arterial segments may be associated with absence of normal perforating branches, and occlusion of these segments can, thus, be performed without further damage to perforating territories. Biondi et al. [23] reported 4 patients harbor large and giant PCA aneurysms treated with occlusion of the parent artery without aneurysm sac occlusion, and following angiographic results presented no recanalization in all cases. In our present series, two large aneurysms treated with proximal occlusion for fearing of mass effect after trapping procedure or perforation of the fragile aneurysmal wall, the results were excellent without residual flow from collateral anastomosis. We suggested that proximal PAO at the level of the aneurysm without the insertion of coils into the aneurysm would increase shrinkage and resorption of dissecting aneurysms. Basically, a test occlusion can be performed to evaluate the patient's capability to tolerate permanent occlusion. Park et al. repored that six of the ten patients who received a PAO without a balloon test occlusion (BTO) experienced PCA territory infarction, whereas only one of the five patients who received a PAO after passing the BTO experienced an infarction. thus, they stated that BTO before PAO was helpful in identifying candidates who truly needed surgical revascularization [11]. But we did not perform test occlusion prior to treatment in our series. Due to performing the test occlusion may carry certain additional risks of thromboembolic complications, especially for patients with recent hemorrhage. Additionally, clinical determinations of the tolerance to test occlusion can be confusing and have unreliable predictive value $[13,24]$.

\section{Other endovascular techniques}

Current advancements in self-expandable neurovasular stents and flow-diverting devices (FDSs) are expected to broaden the application of the endovascular option in the management of PCA aneurysms. However, in 38 cases of PCA aneurysms treated using stents reviewed by Zhao et al. [21], the periprocedural complications and procedure-related mortality was 15.8 and 5.3\%, respectively. Moreover, the immediate angiography showed $50 \%$ was not totally occluded, and $13.0 \%$ aneurysms recurred in angiographic follow-up, which are the risk factors for rupture, especially in dissecting one. Recently, in spite of the use of FDSs has been rapidly popularized with increasing reports of their remarkable ability to reconstruct the neck of large, complex intracranial aneurysms, the outcomes for FDS treatment of PCA aneurysms are relatively unknown [25]. Furthermore, these devices therapy require a prompt antiaggregation therapy which has been proven not safety in acutely ruptured aneurysm. 
Our study has several limitations. Firstly, the small sample of our series may be insufficient to capture the true nature of those aneurysms. Secondly, almost half of patients lost to angiographic follow-up may contribute to the attrition bias, which limit its truth. Thirdly, the lack of a safe and reliable evaluation tool to predict the tolerance of vessel occlusion remains a serious issue. However, what we report here is a study which may serve as a reference for such aneurysms and provide the basis for future studies.

\section{Conclusion}

Dissecting distal PCA aneurysms are rare lesions with a high propensity for bleeding and continue to pose a unique clinical challenge. Although advances in micromaterials and endovascular techniques allow selective occlusion in most of intracranial aneurysms, the results of our study indicate that PAO remains an efficient and relatively safe strategy with acceptable risk of ischemic complications in the distal PCA dissecting aneurysms which tend to recanalize if treated palliatively.

\section{Abbreviations \\ PCA: Posterior cerebral artery; PAO: Parent artery occlusion; CT: Computed tomography; GOS: Glasgow Outcome Scale; DSA: Digital subtraction angiography; SAH: Subarachnoid hemorrhage; MRI: Magnetic resonance imaging; BTO: Balloon test occlusion; FDSs: Flow-diverting devices}

\section{Acknowledgement}

This study was supported by Department of Interventional Neuroradiology at Tiantan Hospital, and Beijing Neurosurgical Institute, Capital Medical University.

\section{Funding}

This research was supported by the Natural Science Foundation of Beijing, China (No.7142032), and Specific Research Projects for Capital Health Development (2014-3-2044).

\section{Authors contributions}

Conceived and designed the experiments: AL. Performed the experiments: ZQ, XF. Analyzed the data: ZQ HK. Contributed reagents/materials/analysis tools: XW WX YL CJ. Wrote the paper: ZQ, XF. Revised the manuscript: ZW. All authors read and approved the final manuscript.

\section{Competing interests}

The authors declare that they have no competing interests.

\section{Consent for publication}

The study protocol was approved by the institutional review board at our hospital. In this study, consent to publish had been obtained from that patients, or in the case of children, their parent or legal guardian.

\section{Ethics approval and consent to participate}

This study was approved by the local human ethics committee of our institution, and informed consent was obtained from all participants. This study was carried out in accordance with the Declaration of Helsinki.

\section{Data availability statement}

All relevant data are within the paper.

Received: 11 June 2016 Accepted: 8 December 2016

Published online: 06 February 2017

\section{References}

1. Lv X, Li Y, Jiang C, Yang X, Wu Z. Parent vessel occlusion for P2 dissecting aneurysms of the posterior cerebral artery. Surg Neurol. 2009;71(3):319-25.
2. CL Sturiale,CD Waure,GMD Pepa,GE Calabrò,A Albanese, D'Argento, F,Fernandez E,Olivi A,Puca A,Pedicelli A,Marchese E. Endovascular Treatment of the Posterior Cerebral Artery Aneurysms: Single-Center Experience and a Systematic Review. World Neurosurgery 2016. DOI: 10. 1016/j.wneu.2016.03.083.

3. Zumofen DW, Shapiro M, Becske T, Raz E, Potts MB, Riina HA, Nelson PK. Endoluminal reconstruction for nonsaccular aneurysms of the proximal posterior cerebral artery with the pipeline embolization device. AJNR Am J Neuroradiol. 2015;36:1299-302.

4. Terasaka S, Sawamura Y, Kamiyama H, Fukushima T. Surgical approaches for the treatment of aneurysms on the $\mathrm{P} 2$ segment of the posterior cerebral artery. Neurosurgery. 2000;47:359-64.

5. Wang $Y$, Lou $X, L i Y$, et al. Imaging investigation of intracranial arterial dissecting aneurysms by using $3 \mathrm{~T}$ high-resolution MRI and DSA: from the interventional neuroradiologists' view. Acta Neurochir (Wien). 2014;156: 515-25.

6. Wakhloo AK, Mandell J, Gounis MJ, et al. Stent-assisted reconstructive endovascular repair of cranial fusiform atherosclerotic and dissecting aneurysms: long-term clinical and angiographic follow-up. Stroke. 2008; 39:3288-96.

7. Liu L, He H, Jiang C, LV X, Li Y. Deliberate parent artery occlusion for non-saccular posterior cerebral artery aneurysms. Interv Neuroradiol. 2011:17:159-68.

8. Hamada J, Morioka M, Yano S, Todaka T, Kai Y, Kuratsu J. Clinical features of aneurysms of the posterior cerebral artery: a 15-year experience with 21 cases. Neurosurgery. 2005;56:662-70.

9. Goehre F, Jahromi BR, Hernesniemi J, Elsharkawy A, Kivisaari R, et al. Characteristics of posterior cerebral artery aneurysms: an angiographic analysis of 93 aneurysms in 81 patients. Neurosurgery. 2014;75:134-44

10. Ferrante L, Acqui M, Trillo G, Lunardi P, Fortuna A. Aneurysms of the posterior cerebral artery: do they present specific characteristics? Acta Neurochir (Wien). 1996;138:840-52.

11. Park W, Kwon do H, Ahn JS, Lee SH, Park JC, et al. Treatment strategies for dissecting aneurysms of the posterior cerebral artery. Acta Neurochir (Wien). 2015;157:1633-43

12. Ciceri EF, Klucznik RP, Grossman RG, Rose JE, Mawad ME. Aneurysms of the posterior cerebral artery: classification and endovascular treatment. AJNR Am J Neuroradiol. 2001:22:27-34.

13. Qin X, Xu F, Maimaiti Y, Zheng Y, Xu B, et al. Endovascular treatment of posterior cerebral artery aneurysms: a single center's experience of 55 cases. J Neurosurg. 2016;22:1-12

14. Horie N, Kawahara I, Kitagawa N, et al. Recanalization after endovascular occlusion of a dissecting aneurysm of the posterior cerebral artery-A case report and review of the literature. Clin Neurol Neurosurg. 2008;110:411-5.

15. Ihn YK, Sung JH, Byun JH. Antegrade recanalization of parent artery after internal trapping of ruptured vertebral artery dissecting aneurysm. J Korean Neurosurg Soc. 2012;51:301-4.

16. Mitsos AP, Corkill RA, Lalloo S, Kuker W, Byrne JV. Idiopathic aneurysms of distal cerebellar arteries: endovascular treatment after rupture. Neuroradiology. 2008;50:161-70.

17. Eddleman CS, Hurley MC, Bendok BR, et al. Cavernous carotid aneurysms: to treat or not to treat? [J]. Neurosurgical Focus. 2009;26(5):E4.

18. Ferns S P, van Rooij W J, Sluzewski M, et al. Partially thrombosed intracranial aneurysms presenting with mass effect: long-term clinical and imaging follow-up after endovascular treatment.[J]. Ajnr American Journal of Neuroradiology, 2010, 31(7):1197-205

19. Kim YB, Lee JW, Huh SK, Kim BM, Kim DJ. Outcomes of multidisciplinary treatment for posterior cerebral artery aneurysms. Clin Neurol Neurosurg. 2013:115:2062-8.

20. Kashiwazaki D, Ushikoshi S, Asano T, Osanai T, Kuroda S, Houkin K. Endovascular treatment for aneurysms of the posterior cerebral artery: 12 years' experience with 21 cases. Acta Neurochir (Wien). 2011;153:2151-8.

21. Huang Q, Liu J, Zhao R, et al. The safety and efficacy of stenting in the treatment of complex posterior cerebral artery aneurysms: a seven-case report and literature review. Clin Neuroradiol. 2013;23:175-87.

22. Wang $H$, Du R, Stary J, et al. Dissecting aneurysms of the posterior cerebral artery: current endovascular/surgical evaluation and treatment strategies. Neurosurgery. 2012;70:1581-8.

23. Biondi A, Jean B, Vivas $E$, et al. Giant and large peripheral cerebral aneurysms: etiopathologic considerations, endovascular treatment, and long-term follow-up. AJNR Am J Neuroradiol. 2006;27:1685-92. 
24. Jayakumar PN, Desai S, Srikanth SG, Ravishankar S, Kovoor JM. Relevance of occlusion test in endovascular coiling of posterior cerebral artery ( $\mathrm{p} 2$ segment) aneurysms. Interv Neuroradiol. 2004;10:235-48.

25. Arrese I, Sarabia R, Pintado R, Delgado-Rodriguez M. Flow-diverter devices for intracranial aneurysms: systematic review and meta-analysis. Neurosurgery. 2013;73:193-9.

Submit your next manuscript to BioMed Central and we will help you at every step:

- We accept pre-submission inquiries

- Our selector tool helps you to find the most relevant journal

- We provide round the clock customer support

- Convenient online submission

- Thorough peer review

- Inclusion in PubMed and all major indexing services

- Maximum visibility for your research

Submit your manuscript at www.biomedcentral.com/submit 